\title{
Walter Benjamin e o contador de histórias: (re)fundação do conto como gênero crítico
}

Patricia Gissoni de Santiago Lavelle

\begin{abstract}
Resumo
Contemporâneo de Dostoievski e de Tolstoi, Nicolai Leskov viveu e escreveu na época de apogeu do romance russo do século XIX. Entretanto, ao caracterizá-lo, logo nas primeiras linhas de seu célebre ensaio de 1936, Walter Benjamin o assimila à figura arcaica do contador de histórias, cujas origens pré-modernas se enraízam na tradição oral, na transmissibilidade da experiência de vida (Erfahrung), a qual estaria irremediavelmente perdida no mundo moderno. Assim, ele situa Leskov num passado anterior ao da modernidade que, no século $X I X$, encontra sua expressão literária no romance burguês. O anacronismo não é arbitrário: o contista russo se serve, de fato, de formas narrativas tradicionais que se alimentam de um farto material popular, e em particular da tipologia do conto de fadas. Entretanto, a partir da leitura de seus contos, Benjamin propõe a fundação de um novo gênero, radicalmente moderno, sobre as ruinas da arte de contar histórias. Para isto, ele explora e potencializa a produtividade reflexiva instaurada pela narrativa tradicional não apenas teoricamente, num ensaio crítico, mas também numa instigante produção ficcional.

Palavras-chave: Conto como Gênero; Crítica, Produtividade Reflexiva; Experiência; Modernidade.
\end{abstract}

Recebido em 21 de abril de 2017 Aceito em 13 de julho de 2017

aProfessora do Departamento de Letras da PUC-Rio. Doutora em filosofia pela EHESS-Paris. E-mail: patricia.g.lavelle@gmail.com 


\section{A crítica: um gênero entre literatura e filosofia}

A geração de intelectuais alemães que ainda fora à escola num bonde puxado por cavalos e se formara no rigor sistemático do neokantismo acedeu à maioridade intelectual depois da catástrofe representada pela Primeira Guerra e pelas transformações sociais e econômicas que dela decorreram. Marcada pela guerra e pela inflação, essa geração se confrontou com o fracasso dos grandes sistemas do século XIX e da concepção, de cunho hegeliano, da modernidade como ponto culminante do progresso da razão na História. $\mathrm{O}$ novo interesse pelo tema da vida e da experiência vivida e o retorno a ideias e formas pré-modernas, evocados pelo próprio Benjamin em "Experiência e pobreza", acompanham assim a descrença na exposição demonstrativa da reflexão filosófica e o interesse por novas formas de apresentação do pensamento. Nesse sentido, a obra de Benjamin é emblemática de uma atitude intelectual compartilhada por outros pensadores de sua geração, como Ernst Bloch ou Theodor W. Adorno, embora tenha também afinidades com projetos literários contemporâneos que enfatizam, inversamente, a reflexividade contida na obra de arte.

Em "Experiência e pobreza", ele se refere à aparição de temas e formas pré-modernas nas ruas das grandes cidades pintadas por Ensor, qualificando tal efeito como fantasmagoria:

Uma nova miséria surgiu com esse monstruoso desenvolvimento da técnica, sobrepondo-se ao homem. A angustiante riqueza de ideias que se difundiu entre, ou melhor, sobre as pessoas, com a renovação da astrologia e da ioga, da Christian Science e da quiromancia, do vegetarismo e da gnose, da escolástica e do espiritualismo, é o reverso dessa miséria. Porque não é uma renovação autêntica que está em jogo, e sim uma galvanização. Pensemos nos esplêndidos quadros de Ensor, nos quais uma grande fantasmagoria enche as ruas das metrópoles: pequenos burgueses com fantasias carnavalescas, máscaras disformes brancas de farinha, coroas de folhas de estanho, rodopiam imprevisivelmente ao longo das ruas. Esses quadros são talvez a cópia da Renascença terrível e caótica na qual tantos depositaram suas esperanças. (BENJAMIN, 1993, p. 115)

Podemos comparar as fantasmagorias de Ensor, tal como Benjamin as apresenta aqui, à sua própria atitude diante do contador, compreendida como uma figura arcaica, 
pré-moderna - espectro que faz aparição e deixa traços na modernidade de sua obra. Ora, se em "Experiência e pobreza", ele valoriza positivamente a barbárie moderna, propondo um construtivismo vanguardista capaz de partir do ponto zero de experiência, o ensaio sobre Leskov assume um tom inegavelmente nostálgico que parece contradizer a primeira posição. Entretanto, o novo bárbaro disposto a construir com pouco e o contador que encontra na riqueza da experiência transmissível a matéria de sua arte são as duas faces de um mesmo. Ao evocar o arcaísmo da narrativa que se inscreve na tradição oral, Benjamin tem o projeto de construir uma nova forma profundamente moderna. De fato, ele não se refere à narrativa apenas teoricamente, no gênero do ensaio crítico, mas também numa produção ficcional na qual as estratégias tradicionais da arte de contar são mobilizadas e ironizadas. Como mostra Marc de Launay (2012) no estudo que acompanha uma coletânea de contos de Benjamin por ele traduzidos em francês, tais textos ficcionais se caracterizam pelo efeito de choque causado pela evocação nostálgica e pela brusca denúncia da nostalgia, pelo uso de formas narrativas tradicionais e por sua ironização pelo contista moderno, que não pode aderir substancialmente a elas.

Procuraremos mostrar que, em sua reflexão teóricoliterária, essa forma arcaica aparece como uma fantasmagoria capaz de reatualizar algo que o sistema filosófico do século XIX negligencia, apontando para um projeto alternativo de modernidade também no nível do pensamento. Esse estudo da narrativa em Benjamin pressupõe, portanto, a compreensão prévia da fecundidade das passagens entre literatura e filosofia exploradas por seus trabalhos.

É na perspectiva da relação entre literatura e filosofia que, numa carta de 1920, endereçada à Ernst Schoen, antigo camarada de estudos, Benjamin circunscreve o vasto campo da crítica:

Muito me interessa, efetivamente, o princípio do grande trabalho crítico-literário: o campo compreendido entre arte e filosofia propriamente dita, que compreendo apenas como o pensamento ao menos virtualmente sistemático. É preciso conceber um princípio perfeitamente originário de uma forma literária a qual pertencem grandes obras como o diálogo de Petrarca sobre o desprezo do mundo ou os aforismas de 
Nietzsche ou as obras de Péguy. Nestas últimas, por um lado, e por outro no devir e nas relações de uma jovem pessoa minha conhecida tal questão se colocou sob meus olhos. Além disso, tornei-me consciente do fundamento originário e do valor da crítica também em meu próprio trabalho. Neste sentido, a crítica de arte, cujas fundamentações me ocuparam, é apenas uma parcela deste vasto domínio." (BENJAMIN, 2000a, p. 71 [252], tradução nossa)

Ao apresentar a crítica como o princípio de um gênero ou um campo de pesquisa, Benjamin nela situa seus próprios trabalhos. Desse campo limítrofe entre literatura e filosofia, a crítica de arte - que procurara conceituar em sua tese de doutorado sobre o primeiro romantismo, defendida em 1919, e no ensaio sobre As Afinidades eletivas de Goethe, publicado em 1922 - seria apenas uma parte. Entretanto, essa parte indica o princípio da zona limítrofe entre literatura e filosofia que constitui o gênero crítico pois pressupõe a correlação entre a dimensão teórica inerente à arte e o elemento estético no discurso filosófico. O conceito benjaminiano de crítica, que se inspira diretamente nos românticos, seria fundamentalmente tributário da estética kantiana, isto é, da correlação descoberta por Kant (1995) entre a produção simbólica do gênio e a apresentação das ideias da razão, entre criação artística e reflexão teórica.

Definido no parágrafo 49 da terceira crítica como a faculdade de criar "ideias estéticas", o gênio corresponde ao talento de articular princípios racionais a representações da imaginação em configurações sensíveis que, abrindo perspectivas à perda de vista para o pensamento, constituem o contrário e o correlato das ideias racionais. Se as ideias estéticas são representações sensíveis às quais nenhum conceito determinado pode corresponder, as ideias da razão são conceitos indeterminados aos quais nenhuma representação sensível pode ser adequada. Assim, ao explicitar a dimensão estética ou simbólica de toda reflexão filosófica, Kant chama a atenção também para a dimensão reflexiva da arte, sua abertura ao pensamento.

A tese de doutorado de Benjamin, que se apoia sobretudo em Friedrich Schlegel e em Novalis, define o conceito romântico de crítica como autoconsciência da reflexão que se coloca em forma numa formação artística. Assim, criticar significa 
desenvolver a reflexão que já se encontra na obra, isto é, despertar e completar o pensamento nela colocado em forma. Segundo a interpretação de Benjamin, para os românticos, a crítica não é um julgamento sobre a obra, mas um método de seu acabamento pois deve ultrapassá-la em sua própria reflexão, torná-la absoluta. Assim, o conceito romântico de crítica de arte se funda sobre a dimensão reflexiva imanente à formação artística, sua criticabilidade essencial. Nesta perspectiva, aquilo que os românticos chamavam de ironia corresponde à exacerbação formal do elemento crítico contido na própria forma da obra de arte, isto é, à acentuação reflexiva de sua reflexividade.

O ensaio "Sobre As Afinidades eletivas de Goethe" funciona como uma crítica paradigmática na qual Benjamin elabora o seu próprio conceito de crítica, inspirando-se nos românticos. A terceira parte desse texto é dedicada ao problema da relação entre arte e filosofia. Segundo Benjamin (2009), as obras de arte são figuras nas quais aparece o Ideal do problema filosófico definido como o conceito de uma pergunta inexistente sobre a unidade da filosofia, isto é, como fundamento unitário de todo questionamento filosófico. De acordo com ele, o Ideal do problema não se encontra numa multiplicidade de problemas, mas está encerrado na pluralidade das obras de arte e sua extração seria tarefa da crítica. Assim, em cada obra de arte verdadeira pode ser encontrada uma manifestação do Ideal do problema filosófico e a crítica o apresenta ao se confrontar com o mistério de sua beleza.

\footnotetext{
“Diante [...] de todo belo, a ideia do desvelamento converte-se naquela da impossibilidade de desvelamento. Essa é a ideia da crítica de arte. A tarefa da crítica de arte não é tirar o envoltório, mas antes elevar-se à contemplação do envoltório enquanto envoltório". (BENJAMIN, 2009, p. 112)
}

A crítica não desvela um conteúdo qualquer que estaria escondido na forma artística, mas ela revela precisamente a dissolução dessa dicotomia na contemplação do belo. Tais formulações, que se referem ao conceito do Belo em Kant, se inscrevem no horizonte inaugurado pela correlação que a Crítica da faculdade de julgar estabelece entre ideia estética e ideia racional, representação artística e questionamento filosófico. Entretanto, Benjamin a considera do ponto de vista de uma 
teoria da linguagem que compreende a ideia como nome, isto é, como algo que diz respeito à dimensão simbólica da linguagem.

De acordo com o "Prefácio crítico-epistemológico" de seu livro sobre o drama barroco, a cristalização da reflexão sobre aquelas questões fundamentais, embora sem resposta, que a filosofia coloca sempre de novo se apresenta em configurações discursivas historicamente condicionadas nas quais o elemento conceitual se articula necessariamente a construções poéticoliterárias. Nesta perspectiva, seu segredo, que se enraíza na vida do pensamento, remete à unidade de forma e conteúdo que também caracteriza a beleza da obra de arte. A crítica literária apresenta assim o problema da apresentação do pensamento em sua relação com a capacidade da linguagem de se articular poeticamente; problema que, embora tenha sido indicado por Kant, é negligenciado pela exaustividade demonstrativa do sistema filosófico do século XIX.

Neste sentido, o conceito de crítica leva-nos a pensar a fecundidade da interseção entre literatura e filosofia que constitui o princípio do trabalho crítico-literário evocado por Benjamin. A arte de contar, abordada tanto no ensaio crítico sobre Leskov quanto numa produção ficcional, se inscreve neste horizonte de problematização da apresentação do pensamento que busca em elementos arcaicos uma alternativa ao projeto de modernidade baseado na ideia de progresso racional e na instrumentalização da linguagem no sistema.

Ora, esta forma pré-moderna, já evocada no ensaio sobre As Afinidades eletivas por meio da história contada aos personagens de Goethe - conto dentro do romance ao qual Benjamin atribui uma grande importância, considerando-o como uma chave de leitura para a compreensão da obra -, nos coloca diante da questão moral. Nesta forma mais arcaica representada pela narrativa, Benjamin identifica o "núcleo luminoso" que se abre à esfera da liberdade da qual os personagens do romance, cativos das convenções como de uma segunda natureza mítica, estão excluídos. Neste sentido, a conclusão do conto é significativa: o jovem enamorado não hesita em mergulhar em águas agitadas para salvar a moça que, num ato desesperado, joga-se do barco. Ao interpretar esse ato heroico - e o episodio no qual o rapaz desnuda o corpo da amada, não para contemplar sua beleza, mas no intuito de salvar-lhe vida -, Benjamin chama a atenção para o abandono 
da esfera do belo em função de uma ordem mais alta. Como veremos, tanto sua reflexão teórica sobre a narrativa quanto o recurso ficcional a estratégias próprias à arte de contar se inscrevem na perspectiva do enraizamento de todo o pensar na esfera da liberdade e na interrogação sobre o sentido da ação humana.

\section{A produtividade reflexiva da arte de contar}

Contemporâneo de Dostoievski e de Tolstoi, Nicolai Leskov viveu e escreveu na época de apogeu do romance russo do século XIX. Entretanto, ao caracterizá-lo, logo nas primeiras linhas do ensaio de 1936, Benjamin o assimila à figura arcaica do contador de histórias, cujas origens pré-modernas se encontram na tradição oral, na transmissibilidade da experiência da vida, a qual estaria irremediavelmente perdida no mundo moderno. Assim, ele situa Leskov num passado anterior ao da modernidade que, no século XIX, encontra sua expressão literária no romance burguês e sua forma filosófica no sistema. $\mathrm{O}$ anacronismo não é arbitrário - o contista russo se serve efetivamente de formas narrativas tradicionais que se alimentam de um farto material popular e da tipologia do conto de fadas -, mas indica a orientação mais geral do estudo como caracterização da figura arcaica do contador de histórias em sua relação com a modernidade.

O contador é um espectro. Aparição do passado no presente, essa figura construída em torno de Leskov no ensaio de 1936 não é uma simples metáfora, mas possui uma certa materialidade que se encarna não apenas no escritor russo, mas também na obra de Hebel, de Poe ou de Kipling, entre outros autores citados. Sobre o projeto do ensaio sobre o contador, que pode ser compreendido como a produção de uma fantasmagoria, Benjamin se exprime em duas cartas de 1936.

Numa carta de Paris, endereçada à Werner Kraft, afirma: "Tenho me ocupado sobretudo com um estudo sobre Nikolai Leskov no qual falo menos sobre este grande contista russo do que sobre o tipo do contador em geral, sua relação com o romancista e com o jornalista e seu lento desaparecimento da face da terra" (BENJAMIN, 2000b, p. 289 [1041], tradução nossa). Uma semana mais tarde, torna a escrever sobre o assunto, desta vez dirigindo-se a Adorno: “Escrevi nos últimos tempos 
um trabalho sobre Nikolai Leskov, o qual, sem se referir, nem mesmo de longe, à teoria da arte, contém alguns paralelos com a "perda da aura" no que esta diz respeito à arte do contador de histórias" (BENJAMIN, 2000b, p. 307 [1047], tradução nossa).

Apresentada como uma forma fundamentalmente aurática cujo declínio no mundo moderno estaria relacionado à emergência do romance e sobretudo da informação, a narrativa tem um caráter artesanal. Isto significa que ela se alimenta da experiência de vida (Erfahrung) do contador, cuja marca se imprime na história contada "como o oleiro deixa a impressão de sua mão na argila do vaso" (BENJAMIN, 1991b, p. 447, tradução nossa). A experiência transmissível da tradição é, segundo Benjamin, a fonte a que recorreram todos os contadores. O senso prático é uma característica dessa figura cuja autoridade se funda na sabedoria, "o lado épico da verdade" (BENJAMIN, 1991b, p. 442, tradução nossa). Assim, a arte de contar pressupõe a capacidade de aconselhar, compreendida como o talento para sugerir uma continuação para uma história que está se desenvolvendo. O declínio da narrativa oral estaria relacionado ao empobrecimento desta experiência de vida que outrora garantia o valor dos conselhos e se exprimia em provérbios e ensinamentos morais.

Benjamin caracteriza tal crise por meio do contraste com o romance e com a informação. Se os contos podem ser compartilhados e transmitidos oralmente, a recepção do romance implica a leitura silenciosa pelo indivíduo isolado. É também a perplexidade diante da singularidade individual que orienta o romance; este se interroga fundamentalmente sobre a inefabilidade do sentido de uma vida e sua conclusão corresponde simbolicamente à morte do personagem. A narrativa curta, ao contrário, coloca a questão moral de tal modo que a história não se acaba com o seu fim, mas suscita a interrogação sobre o que aconteceu depois, abrindo-se assim a outras histórias. Segundo Benjamin, o declínio da arte de contar que se enraíza na tradição oral corresponde à emergência do romance, mas se acentua com a própria crise deste, associada à importância crescente da informação, que encontra seu espaço nos jornais. Ora, esta se caracteriza pela proximidade, pela plausibilidade e pela explicação dos fatos. O saber que vem de longe para se transmitir misteriosamente nos contos não tem nenhum valor informativo. $O$ interesse da informação está na 
proximidade, no aqui e agora de eventos que nunca vêm sem numerosas explicações. Nela, nada é deixado ao julgamento do leitor. Por outro lado, segundo Benjamin, a "metade da arte de contar está em despojar de explicações a história contada" (BENJAMIN, 1991b, p. 445, tradução nossa).

A ausência de explicações psicológicas é uma característica fundamental do conto e remete às suas fontes antigas. A propósito disso, Benjamin menciona a história do faraó egípcio Psammenit, contada por Heródoto e comentada por Montaigne.

No décimo quarto capítulo do terceiro livro de suas Histórias, encontra-se um relato que muito nos ensina. É sobre Psammenit. Quando o faraó egípcio foi derrotado e reduzido ao cativeiro pelo rei da Pérsia Cambises, este decidiu humilhar seu prisioneiro. Deu ordens para que Psammenit fosse levado até a rua em que passaria o cortejo triunfal dos persas. E assim fez com que o prisioneiro visse sua filha, reduzida à condição de serva, indo buscar água no poço, com um jarro. Enquanto todos os egípcios se lamentavam com esse espetáculo, Psammenit ficou silencioso e imóvel, com os olhos baixos; e, quando logo depois viu seu filho ser conduzido em cortejo para execução pública, permaneceu imóvel. Mas quando reconheceu na fila dos prisioneiros um de seus antigos servidores, um homem velho e miserável, então bateu na cabeça com os punhos e deu sinais da mais profunda tristeza. (BENJAMIN, 1991b, p. 445, tradução nossa)

Segundo Benjamin, tal relato conserva suas forças depois de tanto tempo justamente porque renuncia a nos dizer o que se passa no coração e no pensamento do rei deposto. É sua concisão, aliada à ausência completa de explicações psicológicas, que nos deixa pensativos. Abrindo-se a uma pluralidade de interpretações e comentários que procuram, em vão, extrair da história uma moral ou um sentido, o conto não se explica numa frase, mas nos leva à multiplicidade difusa de representações que constitui aquilo que Hans Blumenberg chama de "pensatividade".

Em um pequeno texto intitulado "Pensatividade" (Nachdenklichkeit), Blumenberg evoca uma fábula de Esopo para refletir sobre esse estado de espírito ao qual nos leva o conto. Ele o caracteriza como um momento de hesitação no qual nos confrontamos confusamente com aquelas questões a que não podemos responder, mas às quais também não devemos renunciar. Entretanto, a pensatividade se distingue do pensamento porque não conclui, não resolve nenhum 
problema, é apenas uma disposição, um espaço de jogo. Neste sentido, a pensatividade seria, segundo Blumenberg, um adiamento, um prazo dado contra os resultados banais e decepcionantes que o pensamento ordenado pode nos dar quando se interroga sobre a vida e a morte, o sentido e a ausência de sentido, o ser e o nada. Ora, se a filosofia passa por saber disciplinar com método tais questões - e por vezes as proíbe em razão do caráter inatingível de suas respostas -, a pensatividade, essa produtividade suscitada pelo conto, estaria em sua origem. Assim, a conclusão de Blumenberg nos parece extremamente significativa para compreendermos o recurso à narrativa na perspectiva desse gênero crítico que Benjamin situa entre literatura e filosofia.

Blumenberg (2010) afirma que a filosofia deve conservar, senão renovar, algo da origem, vinda do mundo da vida, que encontra na pensatividade. Pois, segundo ele, a filosofia representa uma constatação mais geral de toda cultura, isto é, que devemos respeitar as questões às quais não podemos atribuir uma resposta. Ora, ao evitar explicações, o conto nos ensina tal respeito - e a palavra "respeito" é aqui significativa pois nos remete aos objetos da razão prática. Diante do conto moderno que se alimenta de fontes pré-modernas, como a fábula ou o conto de fadas, descortina-se a esfera da liberdade na qual esses questionamentos aos quais não podemos dar uma resposta adequada encontram sua fonte.

No ensaio sobre o contador, Benjamin afirma que o conto de fadas revela as primeiras medidas tomadas pela humanidade para libertar-se do pesadelo mítico. Dirigindose às origens do homem, o conto de fadas apresenta a figura do justo que não se identifica com o místico asceta, mas com o homem simples e ativo, capaz de enfrentar as adversidades com bondade e astúcia. Benjamin identifica tais elementos na produção de Leskov, o que lhe permite delinear os contornos da figura do contador, fantasmagoria na qual "o justo encontra a si mesmo" (BENJAMIN, 1991b, p. 465, tradução nossa). Segundo ele, o primeiro contador verdadeiro é e continua sendo o do conto de fadas, que sabia dar um bom conselho e oferecer sua ajuda na necessidade provocada pelo mito.

O conto de fadas ensinou há muito tempo a humanidade e ainda hoje ensina as crianças a combater as forças do mundo do mito com astúcia e ousadia. [...] A magia libertadora do 
conto de fadas não coloca em cena a natureza de um modo mítico, mas indica a sua cumplicidade com o ser humano liberado. (BENJAMIN, 1991b, p. 458, tradução nossa)

Levando-nos de volta à infância e aos primeiros esforços da humanidade para libertar-se do mito, o contador nos conduz à origem da filosofia na pensatividade - esse espaço de jogo, essa vivência de liberdade que se abre à esfera da razão prática na qual o questionamento metafísico se enraíza. Assim, a nostalgia inerente ao ensaio sobre o contador não diz respeito apenas ao declínio da arte de contar e ao empobrecimento da experiência que constitui sua fonte, mas concerne também à pensatividade que se instala no sonho acordado, no devaneio - essa face interior do tédio que Benjamin associa ao ritmo do trabalho artesanal. "O tédio é o pássaro de sonho que choca o ovo da experiência" (BENJAMIN, 1991b, p. 446, tradução nossa), diz ele ao afirmar que as atividades artesanais que o propiciavam, prestando-se ao dom de ouvir e à arte de contar, estão em vias de extinção.

\section{Nostalgia e ironia: o conto como gênero crítico}

Vivenciamos o surgimento da short story. Ela se emancipou da tradição oral e não mais permite essa lenta superposição de camadas finas e translúcidas que oferece a melhor imagem da maneira pela qual o conto perfeito vem à luz do dia a partir das camadas acumuladas por suas versões sucessivas. (BENJAMIN, 1991b, p. 448, tradução nossa)

Grande parte da produção ficcional de Benjamin se inscreve nesse novo gênero literário que surge, por assim dizer, nas ruínas da arte de contar. Esses textos curtos, escritos ao longo dos anos vinte e trinta, utilizam elementos que caracterizam a tradição narrativa, tal como é apresentada no ensaio sobre Leskov. Entretanto, se o uso de tais recursos provoca em nós a nostalgia da origem do pensamento na pensatividade, o recurso à ironia marca a distância entre o contista moderno e as formas tradicionais das quais ele se serve, criando assim um efeito de choque. Neste sentido, a barbárie construtivista e a nostalgia da arte de contar correspondem a dois aspectos de um mesmo projeto filosófico-literário no qual o recurso ao arcaico visa encontrar uma alternativa para a imanência radical do mundo moderno. 
Encontramos um exemplo disso em "A cerca de cactos", em que o personagem principal, o irlandês $\mathrm{O}^{\prime}$ Brien, incarna a figura do bárbaro moderno, disposto a começar do zero. $\mathrm{O}$ conto, escrito na primeira pessoa, narra o encontro, em Ibiza, com esse excêntrico solitário cujas ocupações - a pesca, a caça e a arte de fazer e desfazer nós - remetem a um mundo arcaico. Da África, onde convivera com uma tribo primitiva, trouxera uma bela coleção de máscaras que fora roubada por seu melhor amigo havia muitos anos. Assim, o narrador do conto se surpreende ao contemplar um impressionante conjunto de máscaras africanas reunidas em sua casa. O'Brien passa então a contar como vieram parar ali numa dessas noites em que o luar e o tédio estimulam a faculdade de produzir e de perceber semelhanças. Ele vira pela janela uma cerca de cactos ganhar vida e, como um grupo de guerreiros africanos, avançar usando as máscaras desaparecidas. Resolvera então esculpir suas visões oníricas na madeira.

Mas a história não termina com essa invocação nostálgica, na qual o arcaico perdido reaparece no arcaísmo do sonho. A ironia fica reservada a um reencontro posterior com três dessas máscaras numa galeria de arte de Paris, onde especialistas garantem sua antiguidade e autenticidade. Como afirma o galerista, elas poderão "inspirar nossos jovens artistas em suas próprias interessantes pesquisas" (BENJAMIN, 1991c, p. 754). Os contos de Benjamin são como essas máscaras primitivas esculpidas pelo excêntrico O'Brien.

Retorno do passado no presente, a fantasmagoria do contador constitui o próprio tema de "O Lenço". Nesse conto, um marinheiro, o Capitão O..., possui todos os traços que compõem a figura do contador de histórias, menos um, que aparece, no entanto, como fundamental: a faculdade de contar sua própria vida. Tal faculdade, que implica a ligação intrínseca entre a vida do contador e a matéria de suas histórias, corresponde à transmissão da experiência tradicional, essa Erfahrung que não se confunde com as vivências (Erlebnisse) radicalmente individuais e interiorizadas do homem moderno. Ora, o desenrolar do conto contradirá e confirmará essa constatação inicial.

Encontrado por acaso durante uma escala, o Capitão O... contou ao narrador em primeira pessoa do conto que, muitos anos antes, teve como passageira uma moça tão linda quanto 
discreta e silenciosa. Um dia, ela deixou cair no convés um lenço e, quando ele o apanhou, agradeceu seu gesto como se tivesse salvo sua vida. O marinheiro-contador descreve minuciosamente o lenço, que era ornamentado com um escudo bordado de estrelas, mas nada diz sobre seus próprios sentimentos e impressões. Conta apenas que, quando o barco estava para atracar, a bela passageira precipitou-se sem uma palavra e jogou-se no mar, justamente no pequeno espaço que restava entre a quilha e o cais. $\mathrm{O}$ perigo era grande $\mathrm{e}$ a moça teria sido rapidamente esmagada se, num átimo de segundo, alguém não tivesse se prontificado para salvá-la. $\mathrm{O}$ episódio faz pensar na pronta decisão do rapaz que salva sua amada das águas geladas na pequena narrativa que constitui, segundo Benjamin, o núcleo luminoso das Afinidades eletivas de Goethe. Entretanto, o relato do marinheiro, todo na terceira pessoa, não inclui nenhuma alusão aos sentimentos pois não dá lugar a nenhuma explicação psicológica. Neste ponto, a história do Capitão O... é tão reservada e discreta quanto a moça, e sua beleza delicada vem justamente dessa extrema concisão. É a figura arcaica do justo que vemos surgir em sua simplicidade proverbial.

Na contramão do romance psicológico do início do século XX, a short story de Benjamin nada diz sobre a interioridade dos personagens. Sua modernidade radical está na evocação irônica e nostálgica do relato arcaico que apenas expõe, sem nada explicar. Se no final ficamos sabendo que o herói da história é o próprio contador, isso se deve a uma única frase em primeira pessoa: "Enquanto eu assim a segurava [...], ela sussurrou "obrigada" como se lhe tivesse devolvido um lenço" (BENJAMIN, 1991a, p. 744). E a última palavra do conto é confiada justamente a esse objeto cuja presença dispensa maiores explicações: o narrador do conto reconhece o pequeno escudo bordado no lenço que o Capitão agita ao longe, ao despedir-se.

Ao tematizar o próprio contador, evocando o seu espectro, Benjamin ironiza a forma narrativa. Penso aqui no conceito romântico de ironia como um recurso formal, um distanciamento crítico que se inscreve na própria forma da obra, explicitando a reflexão nela contida e relativizando o seu caráter condicionado. 
Não é por acaso que esse conto sobre o contador se abre com a interrogação sobre o declínio da própria arte de contar. $\mathrm{O}$ narrador da pequena ficção começa por relacionar a morte da narrativa com o desaparecimento das atividades manuais e repetitivas que outrora deixavam tempo para o tédio. Assim, ao incluir no conto tradicional a própria teoria de seu declínio, distancia-se da simplicidade "ingênua" (no sentido de Schiller) que nos toca no relato de Heródoto, ou mesmo nos contos de Leskov ou de Hebel. A short story do início do século XX, tal como Benjamin a inventa, é um gênero "sentimental". Isso quer dizer que, nele, a ironização dos procedimentos tradicionais da arte de contar implica não apenas a consciência de seu fim, e, portanto, uma certa nostalgia, mas também a reflexão sobre sua reflexividade.

\section{REFERÊNCIAS}

BENJAMIN, Walter. Das Taschentuch. In: . Gesammelte Schriften, Band IV-2, Frankfurt: Suhrkamp Verlag, 1991a.

. Der Erzähler. Betrachtungen zum Werk Nikolai Lesskows. In: Gesammelte Schriften, Band II-2, Frankfurt: Suhrkamp Verlag, Gesammelte Schriften. 1991b

. Die Kaktushecke. In: . Gesammelte Schriften, Band IV-2, Frankfurt: Suhrkamp Verlag, 1991c.

Erfahrung und Armut. In: . Gesammelte Schriften, Band II-1, Frankfurt: Suhrkamp Verlag, 1991d.

. Experiência e Pobreza. In: Magia e técnica, arte e política. Tradução de Sérgio Paulo Rouanet. São Paulo: Brasiliense, 1993. (Obras Escolhidas, v. 1).

. Gesammelte Briefe, Band II, Frankfurt: Suhrkamp Verlag, 2000a.

. Gesammelte Briefe, Band V, Frankfurt: Suhrkamp Verlag, 2000b.

. Geschichten und Novellistisches. In: . Gesammelte Schriften, Band IV-2, Frankfurt: Suhrkamp Verlag, 1991e.

. Goethes Wahverwandtschaften. In: Gesammelte Schriften, Band I-1, Frankfurt: Suhrkamp Verlag, 1991f 
O Narrador. In: . Magia e técnica, arte e política.

Tradução de Sérgio Paulo Rouanet. São Paulo: Brasiliense, 1993. (Obras Escolhidas, v. 1).

Sobre As Afinidades eletivas de Goethe. In:

Ensaios reunidos: Escritos sobre Goethe. Tradução de Mônica Kauz Bornebusch, Irem Aron, Sidney Camargo. São Paulo: Duas cidades/Editora 34, 2009.

BLUMENBERG, Hans. Pensivité. Tradução de Denis Trierweiler. In: Cahiers Philosophiques (Dossier Hans Blumenberg, org. Michèle Cohen-Halimi), $n^{\circ}$ 123/4 trimestre, 2010.

KANT, Emanuel. Crítica da faculdade de juízo. Tradução de Valério Rohden e Antônio Marques. Rio de Janeiro: Forense Universitária, 1995.

LAUNAY, Marc (de). Préface. In: BENJAMIN, Walter. N'oublie pas le meilleur et autres histoires et récits. Tradução, apresentação e notas por Marc de Launay. Paris: L’Herne, 2012. 


\section{Abstract \\ Walter Benjamin and the Storyteller: recreation of the short story as a critical genre}

Nicolai Leskov lived and wrote at the glorious time of the nineteen-century's Russian roman; he was a contemporary of Dostoyersky and Tolstoy. But in his essay about the author, Walter Benjamin compares him to the archaic figure of the Storyteller. The origins of that figure are pre-modern and are connected with oral tradition and traditional transmission of experience (Erfahrung), which are lost in modern world. So, he places Leskov in the archaic past of the oral tradition. The anachronism is not absurd: the Russian Storyteller uses traditional and popular forms like fairy tales. But the position of Benjamin is not nostalgic or conservative. Reflecting on Lescov's short stories, he intends to create a new genre, radically modern, with the ruins of the storytelling art. He explores the reflexive productivity of the traditional tale not only as a critic but also as a fictionist.

Keywords: "Short story" as a Genre; critic; Reflective Productivity; Experience; Modernity. 